\title{
Production of Exopolysaccharides by Strains of
}

Streptococcus thermophilus

UMI PURWANDARI ${ }^{1 *}$ AND TODOR VASILJEVIC ${ }^{2}$

'Department of Agroindustrial Technology, Faculty of Agriculture, Universitas Trunojoyo Madura, Indonesia,
PO Box 2. Kamal 2, Kamal, Madura 69162, Indonesia; 'School of Molecular Sciences, Faculty of Health, Engineering and Science, Institute for Sustainability and Innovation, Victoria University, Werribee Campus, PO Box 14428

Two strains of Streptococcus thermophilus producing capsular and capsular-ropy exopolysaccharides (EPS) were examined for their growth and EPS production in M17 medium supplemented with glucose, galactose or lactose and incubated at 30,37 or $42^{\circ} \mathrm{C}$ for 24 hours Growth parameters (viable cells, OD, lactate production, $\mathrm{pH}$ ) and EPS production were determined. Flow behavior of the EPS dispersions and time. Growth was enhanced by glucose, lactose and higher incubation temperature EPS concentration in the mes dium was greater in the presence of glucose and galactose. Despite the restricted growth conditions, the capsular strain produced comparable levels of EPS to the capsular-ropy strain even under sub-optimal incubation temperature

Key words: Streptococcus thermophilus, exopolysaccharides, growth conditions

Considerable attention has been given to bacterial provide potential health benefits to consumers (Looijesteij et al. 2001) and their application as thickening agents processed products (Cerning 1990). Although certain bacterial species can produce considerable amounts of EPS, yoghurts prepared with strains Streptococcus thermophilus resulted in less than $0.1 \%$ EPS in the final product (Cerning 1990). Nevertheless, EPS play an important role in the development of yoghurt texture, with the type of EPS exerting a greater effect than their concentration Vaningelgem et al. 2004). In general, two strain-dependen types of EPS (Mozzi et al. 2006) have been frequently assessed for their effects on yoghurt texture, namely 'ropy' and 'capsular'. Certain bacterial strains may even produce mix of these two types in various proportions (Zisu and Sha 2003; Zisu and Shah 2005). Furthermore, combinations of the two types of EPS producing cultures improved not only the total EPS production but also yoghurt texture (Marshal and Rawson 1999).

Numerous studies have been conducted in order to enhance our understanding of the factors governing EPS production and the mechanisms by which they affect the yoghurt texture. Most of the EPS produced during yoghur fermentation are heteropolysaccharides, and their production may be unpredictable due to a plasmid-related instability (Boels et al. 2001). EPS production, thickening properties, molecular mass and structural conformation are greatly affected by environmental factors (Ruas-Madiedo al. 2005). In some species, these factors only affected EPS yield, because their monosaccharide composition remaine unchanged (Looijesteijn and Hugenholtz 1999). Strain selection, temperature, $\mathrm{pH}$ and growth stage (Aslim et al. 2005), nitrogen source (Degeest et al. 2002), an metabolizable sugars (Mozzi et al. 2003) are among the factors influencing EPS production. EPS production by some S. thermophilus strains was coupled to growth (Vin et al. 2005). However, in some mesplic bal strains, EPS were mainly produced at sub-optimal growth conditions (Cerning 1990). Depending on the strain and growth conditions, maximum yield of EPS may be achieved in the exponential (Duenas et al. 2003) or stationary growth phase (Gancel and Novel 1994). At the end of growth phase, there are some indications that EPS undergoes undesirable enzymatic degradation (Pham et al. 2000; Degeest et al. 2002). The type of carbon source apparently governs the total amount of EPS produced with a clear straindependence (Mozzi et al. 2001). For example, S. thermophilus LY03 produced more EPS with lactose than with glucose (Degeest and de Vuyst 2000a). Nitrogen compounds in the growth medium are necessary during formation of sugar nucleotides, essential precursors for EPS assembly. However, the type of nitrogen source appears to be less important in EPS production than is the carbon source (Duenas et al. 2003).

Although several types of EPS have been reported to influence yoghurt texture, and some mechanisms on their interactions with milk proteins has been proposed, there is a lack of information on the rheological properties of EPS produced by yoghurt cultures. Such information can be useful for predicting the possible interaction of EPS with milk component(s) to influence the texture of yoghurt. Therefore, this study aimed to examine EPS production by two strains of $S$. thermophilus which produced capsular-ropy and capsular EPS. We reported the effect of fermentation conditions including temperature, time, and carbon source on its production.

\section{MATERIALS AND METHODS.}

Bacterial Strains. The two strains of S. thermophilus examined in the study were kindly provided by Australian S. thermophilus ST 1275 produces mainly , Australia). smaller portion of capsular EPS, while ST 285 produces only 
capsular EPS (Zisu and Shah 2003; 2005). The frozen $\left(-80^{\circ} \mathrm{C}\right)$ cultures in $300 \mathrm{~mL} \mathrm{~L}^{-1}$ glycerol were activated by growing them twice in M17 medium (Amyl Media, Merck Pty Ltd., Kilsyth, Victoria, Australia) at $37^{\circ} \mathrm{C}$ for at least 24 hours.

Medium. The medium used in these experiments was basal M17 medium supplemented with galactose, glucose or lactose at $20 \mathrm{~g} \mathrm{~L}^{-1}$. The cultures were inoculated into $30 \mathrm{~mL}$ of the sterile medium in $50 \mathrm{~mL}$ Falcon tubes (Falcon, Blue Max, Becton Dickinson and Company, Franklin Lakes,

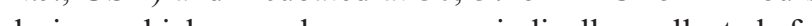
during which samples were periodically collected for analysis of all growth parameters and determination of EPS (a)

Bacterial Counts. Determination of viable cell count was carried out by serial dilutions in sterile $1 \mathrm{~g} \mathrm{~L}^{-1}$ peptone water, and incubation at the corresponding temperature for 24 hours to obtain sufficient cell growth. Cell concentratio was additionally determined based on optical density at

EPS Determination. EPS assessed in the rheological studies were extracted from the culture grown in M17 medium by precipitation with ethanol (van Geel-Schutten et al. 1998). Initially, fermentation was stopped by adding $20 \mathrm{~g} \mathrm{~L}^{-1} \mathrm{TCA}$ and keeping in a cool room $\left(4^{\circ} \mathrm{C}\right)$ overnight. This was followed by protein removal by centrifugation at 11 $000 \times \mathrm{g}$ and $4^{\circ} \mathrm{C}$ for $10 \mathrm{~min}$ (Model J2-HS, Beckman, Fullerton, California, USA). The supernatant was collected and mixed with two volumes of ethanol. The mixture was allowed to stand for twelve hours for complete precipitation of EPS. This procedure was repeated twice, after which the EPS was freeze-dried (Dynavac freeze drier, Dynavac Eng Pty. Ltd, Melbourne, Australia). The

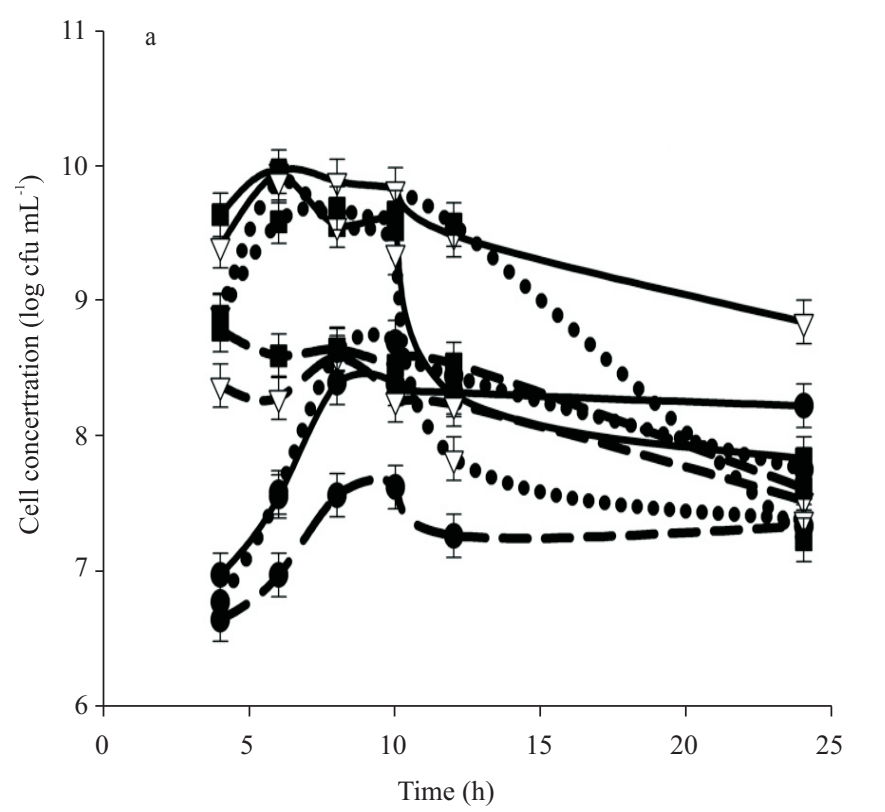

concentration of EPS was assessed using the phenolsulphuric acid method (Dubois et al. 1956). Lactic acid concentration was determined by an HPLC metho (Donkor et al. 2005). The method uses dilute $0.01 \mathrm{~mol} / \mathrm{L}$ $\mathrm{H}_{2} \mathrm{SO}_{4}$ as a mobile phase with flow rate of $0.6 \mathrm{~mL} \mathrm{~min}^{-1}$, and $300 \times 7.8 \mathrm{~mm}$ ion-exchange Aminex HPX-87H column (Bio-Rad Laboratories, Australia) coupled to a UV detector (Varian Analytical Instruments, Walnut Creek, CA, USA) at $220 \mathrm{~nm}$. The column temperature wa maintained at $65^{\circ} \mathrm{C}$

Statistical Analysis. A randomized split plot in time block design was applied to the design of the fermentation experiments. This was set up with four main effects: strai (two levels), sugar types (three levels), temperatures (three levels), and fermentation time (six levels: 0, 3, 6, 9, 12, 2 hours). This design was replicated twice with at least two sub samplings. Results were analyzed using a General Linea Model procedure. The level of significance was set $p=0.05$. The best fit contanional analysis for heologic data was carried out using the Rheoplus software (v2.81, Anton Paar

\section{RESULTS}

Bacterial Counts. Viable cell counts were significantly $(\mathrm{P}<0.05)$ affected by all factors: strain, temperature, type of tion time and their interactions. The capsul strain consistently showed slower growth compared to the capsular-topy culture, regardless of the growth conditions. The maximum cell numbers of the capsular strain we $22 \times 10^{8} \mathrm{CFU} \mathrm{mL}^{-1}$ achieved in glucose-M17 ${ }^{\circ}{ }^{\circ} \mathrm{C}$. In contast, the capsular-ropy culture grew to $1.6 \times 10^{\circ}$

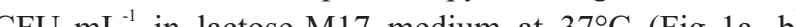
Higher temperaure $\left(37\right.$ and $42^{\circ} \mathrm{C}$ ) at $37{ }^{\circ} \mathrm{C}$ ( growth than at $30^{\circ} \mathrm{C}$ for both strains and all types of sugar.

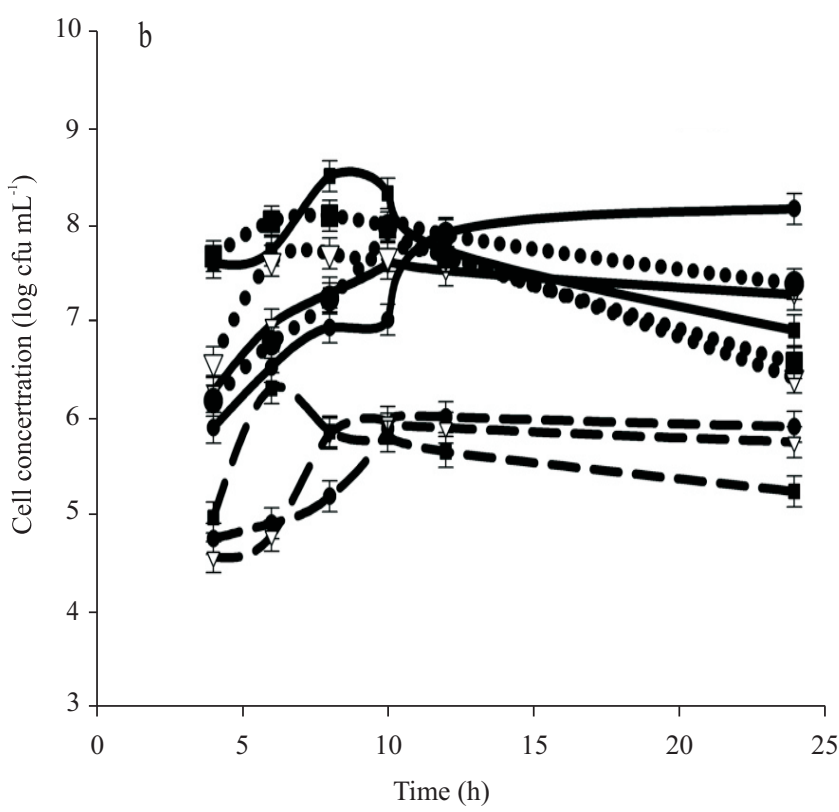

Table 1 Cell growth parameters of the capsular-ropy and capsular source during growth phase

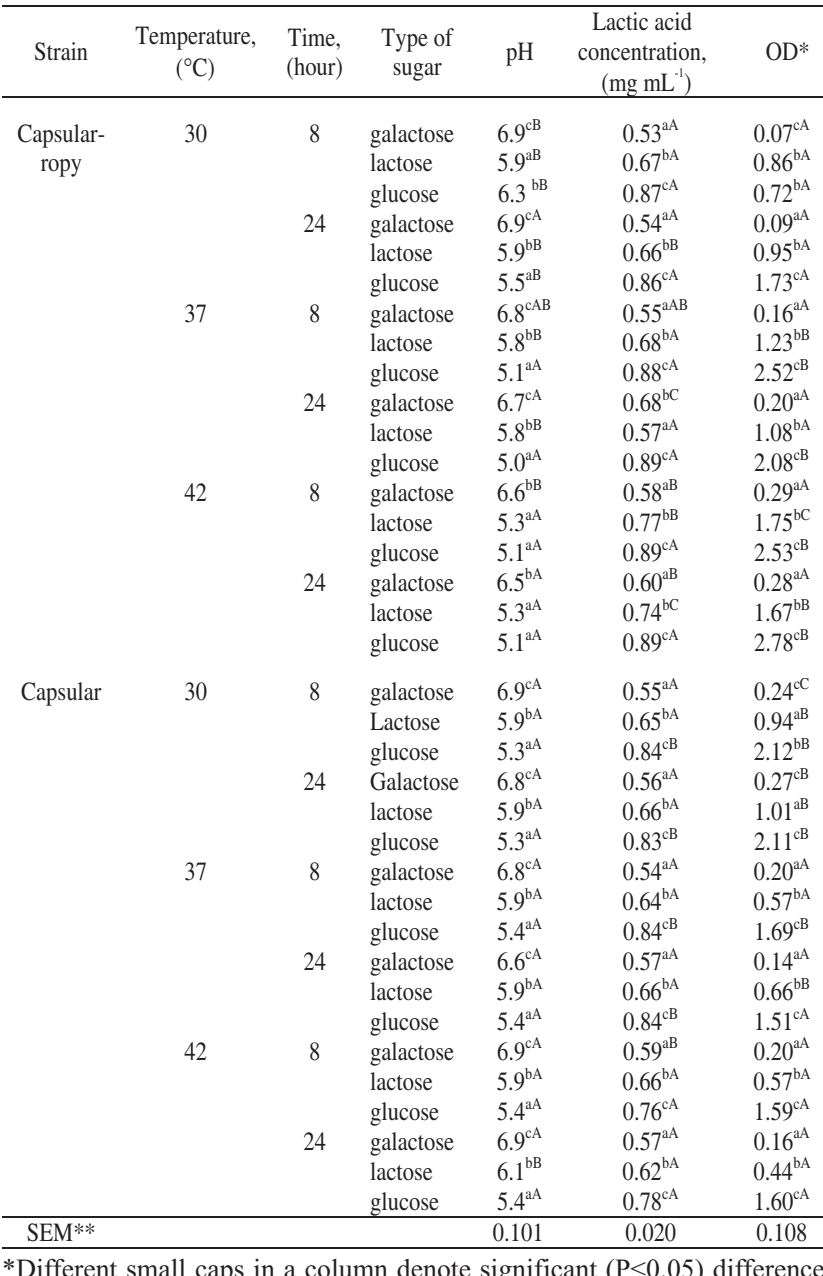

"Different small caps in a colmn denote significant $(\mathrm{P}<0.05)$ differen among means of the same culture, temperature and time but different suge
ypes. The different capital letters depict significant $(\mathrm{P}<0.05)$ difference temperature. **SEM, stamdarderror of means, with $\mathrm{P}=0.05$.

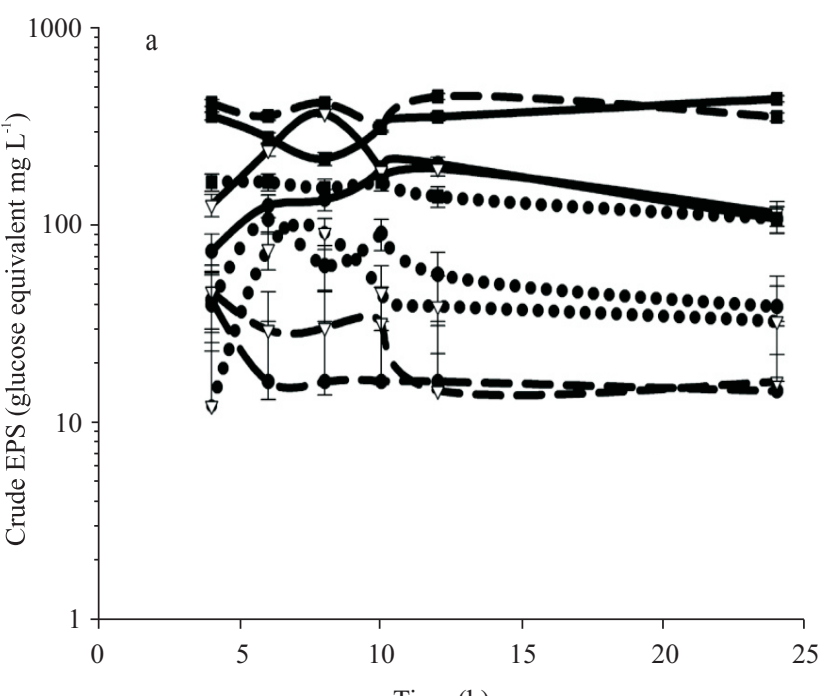

M17 medium containing glucose or lactose was more growth supportive than that with galactose for both strains and in all temperatures.

Positive effects of higher fermentation temperature, glucose or lactose on cell growth was also confirmed by other growth parameters such as optical density, $\mathrm{pH}$ and lactic acid production (Table 1). Statistically, OD readings were only influenced by the type of sugar and its interactions with other factors $(P<0.05)$. Fermentation time and the type of strain individually had no effect on cell growth as measured by OD, but their interactions did $(\mathrm{P}<0.05)$. Sugar type and its interaction with other factors significantly $(\mathrm{P}<0.05)$ affected the final $\mathrm{pH}$ of the medium. Lactic acid concentration was similarly influenced by the factors examined. The types of sugar substantially $(\mathrm{P}<0.05)$ influenced lactate concentration, where glucose produced most lactic acid $\left(\sim 0.80-0.87 \pm 0.020 \mathrm{mg} \mathrm{mL}^{-1}\right)$, whereas galactose produced the lowest levels $\sim 0.55-0.62 \pm 0.02$ $\mathrm{mg} \mathrm{mL}^{-1}$. In most cases, from the 8th hour onwards, lactate concentration was either increased or remained unchanged.

EPS Concentration. The EPS production was only their interactions with other factors $(P<0.05)$. The EPS produced by the two stain $(P<0.05)$. The amount of differ $(P>0,05)$. Maximum EPS concentrign dith by the capsular-ropy strain was $441.0 \pm 36.2 \mathrm{mg} \mathrm{L}$ in

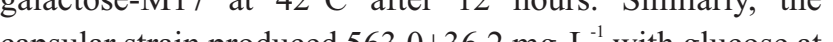
$30^{\circ} \mathrm{C}$ cor strain produced $563.0 \pm 36.2 \mathrm{mg} \mathrm{L}$ with glucose at $30^{\circ} \mathrm{C}$ after 12 hours (Fig 2a, b). EPS production of the capsular strain at all temperatures was relatively high and the differ EPS production was significantly $(\mathrm{P}<0.05)$ affected by incubation time though not statistically significant $(\mathrm{P}>0.05)$, higher temperature tended to enhance $E \mathrm{~S}$ production by the capsular-ropy strain in all types of sugar (Hig 2a,b). On the other hand, the capsular strain appeared to prefer lower

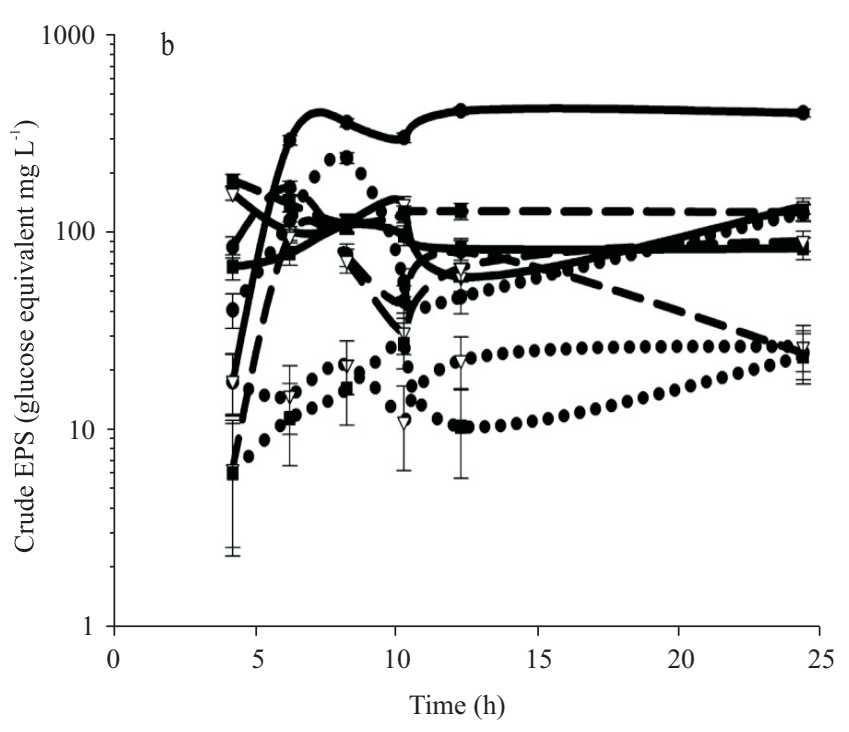


temperature $\left(30^{\circ} \mathrm{C}\right)$ and produced more EPS when grown on glucose or lactose (Fig 2a, b). M17 medium containin galactose poorly supported cell growth, however, the EPS concentration in this medium was relatively high. In medium with lactose at all temperatures, and glucose or galactose at low temperature $\left(30^{\circ} \mathrm{C}\right)$, maximum EPS concentration was reached after 8 hours. Afterwards, the EPS concentration was often slightly reduced towards the end of fermentation. The pattern of EPS production over time by the capsular Ttrin was somewhat similar to that of the capse capropy counterpart, except tha EPS concentration in glato cold $\left(30^{\circ} \mathrm{C}\right)$ remained stationaly a 4 hours. Moreover. EPS concentration in lactose mediun low temperates ( 30 and $\left.37^{\circ} \mathrm{C}\right)$ were low, and did not show any considerable change until the end of fermentation.

\section{DISCUSSION}

Bacterial Counts. Our results are in agreement wit previous work showing comparable cell numbers of $S$. thermophilus grown in lactose- and glucose-containing medium (Degeest and de Vuyst 2000b). In contrast to these findings, van den Bogaard et al. (2000) found that $S$. thermophilus grew poorly on glucose (Poolman 2002). Growth of the S. thermophilus strain in the glucose based medium requires the activity of phosphoglucomutase whose activity may be supressed in the presence of lactose (Levander and Radstrom 2001). Degeest et al. (2000b) also showed that galactose did not support the growth of a $S$. thermophilus strain

EPS Concentration. Our experiment showed that both strains produced considerable amounts of EPS in M1 medium, even higher than as 2006). As in this experiment, no difference in EPS production of both ropy and non-ropy strains was found by Mozzi et al. (2006). Most of S. thermophilus strains posses Leloir system for EPS synthesis (Mora et al. 2002). The thre has reported elsewhere (Chervaux et al. 2000), wit galactose frequenty related to ErS production (Mozzi et al. 2001). Our result was in contrast to previous report tha glucose poorly supported EPS production compared to lactose (Degeest et al. 2000a), but similar to a more recent work (Shene et al. 2008) that EPS production of $S$. thermophilus strain was higher on glucose-containing medium. The growth-ass S. thermophilus strains has been reported previously, wit the EPS produced mainly during logarithmic phase (RuasMadiedo et al. 2005; Shene et al. 2008). The maximun production of EPS seemingly varies with strains and is not always linear with temperature of fermentation, as also shown by previous report (Shene et al. 2008).

Galactose was a predominant (Goh et al. 2005) and consistent (Goh et al. 2005; Mozzi et al. 2006) primary un in the structure of the EPS backbone in several $S$. thermophilus strains, although most of them did not utilize galactose (Mora et al. 2002) or metabolized galactose only a the end of growth phase (de Vin et al. 2005). However, several reports found discrepancies between theoretical values and actual galactose concentration in the medium sugesting a flux to other metablite including loctic acid eve S. thermophilu (de Vin et al. 2005). Galc S. TPS a (Mozi et al 2001). The avalubility of gato ge initiad by the activation of galactose symporter in intiated by the activation of galactose symporter in the (Ponce of lactose (de Vin et al. 2005) or low lase/gactase ratio (Poolsan 2002). Moreover, gactose catabolism is also possible by the activation of (anter

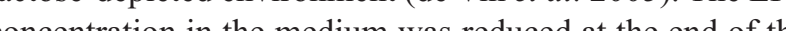
cowth growth phase. ThS could be related to shortage of ATP required for Ers polyenzation (Welman et al. 2006)

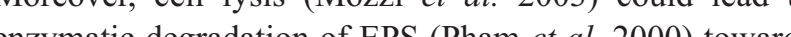
ency estages of the growth.

\section{REFERENCES}

Aslim B, Beyatli Y, Yuksekdag ZN. 2006. Productions and monomer compositions of exopolysaccharides by Lactobacillus delbruect
subsp bulgaricus and Streptococcus thermophilus strains isolated fro traditional home-made yoghurts and raw milk. Int J Food Sci Tec

41:973-9.
Aslim B, Yuksekdag ZN, Beyatli Y, Mercan N. 2005. Exopolysaccharide production by Lactobacillus delbrueckii subsp bulgaricus an World J Microbiol Biotechnol 21:673-7.

Boels IC, Kranenburg R van, Hugenholtz J, Kleerebezem M, Vos WM de. 2001. Sugar catabolism and its impact on the biosynthesis an

erning 1990. Exocellular polysaccharides produced by lactic acid bacteria. FEMS Microbiol Lett 87: 113-30.

(a) Lactobacillus delbrueckii subsp bulgaricus strains in a nove biochemical analysis of the galactose phenotype of dairy Streptococcus thermophilus strains reveals four different fermentation profiles. App

Degeest B, de Vuyst L. 2000a. Correlation of activities of the enzymes $\alpha$ phosphoglucomutase, UDP-galactose 4-epimerase, and UDP-glucose Streptococcus thermophilus LY03. Appl Environ Microbiol 66:3519-

Degeest B, de Vuyst L. 2000b. Correlation of activities of the enzyme lucose pyrophosphorylase with exopolysaccharide biosynthesis by Streptococcus thermophilus LY03. Appl Environ Microbiol 66:3519-

Degeest B, Mozzi F, Vuyst L de. 2002. Effect of medium composition and emperature and $\mathrm{pH}$ changes on exopolysaccharide yields and stability
during Streptococcus thermophilus $\mathrm{LY} 03$ fermentations. Int $\mathrm{J}$ Food Microbiol 19:161-74.

Donkor ON, Henniksson A, Vasiljevic T, Shah NP. 2005. Probiotic strains a starter cultures improve angiotensin-converting enzyme inhibitory activity in soy yogurt.J Food Sc1 70:M375-81.

method for the determination of sugars and related substances. An Chem 28:350-6.

Duenas M, Munduate A, Perea A, Irastorza A. 2003. Exopolysaccharide production by Pediococcus damnosus 2.6 in a semidefined medi
Gancel F, Novel G. 1994. Exopolysaccharide production by Streptococcussalivarius ssp thermophilus cultures: two distinct modes of polymer prod.

Goh KKT, Haisman RD, Singh H. 2005. Examination of exopolysaccharid confocal laser scanning and scanning electron microscopy techniques J Food Sci 70:M224-9.

, Radstrom P. 2001. Requirement for phosphoglucomutase

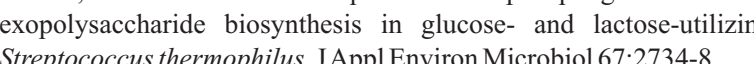

Looijesteijn PJ, Hugenholtz J. 1999. Uncoupling of growth and exopolysaccharide production by Lactococcus lactis subsp. cremor Nizo B40 and optimization of its synthesis. J Biosci Bioeng 88: 178-82.

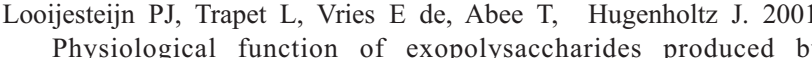
Lactococcus lactis. Int J Food Microbiol 64:71-80.

Marshall VM, Rawson HL. 1999. Effects of exopolysaccharide-producing
strains of thermophilic lactic acid bacteria on the texture of stirre strains of thermophilic lactic acid bactent
yoghurt. IntJ Food Sci Techn 34:137-43.

Mora D, Fortina MG, Parini C, Ricci G, Gatti M, Giraffa G, Manachini PL thermophilus strains isolated from dairy products. J Appl Microbio 93:278-87.

Mozzi F, Giori GS de, Font de Valdez G. 2003. UDP-galactose 4-epimerase A key enzyme in exopolysaccharide formation of Lactobacillus case
CRL 87 in controlled $\mathrm{pH}$ batch cultures.JAppl Microbiol $94 \cdot 175-83$. Mozzi F, Rollán G, Giori GS de, G, Font de Valdez G. 2001. Effect galactose and glucose on the exopolysaccharide production and the
activities of biosynthetic enzymes in Lactobacillus casei CRL 87. J activities of biosynthetic

EM, Van Der Meulen R, Moreno MRF, Font de Valdez G, Vuyst de L. 2006. Diversity of heteropolysaccharide-producing lactic acid bacterium strains and their biopolymers. Appl Eniron Microbic 72.4431 .5$.

, Pupont I, Roy D, Lapointe G, Cerning J. 2000. Production of nzymatic degradation during prolong fermentation. Appl Environ Microbiol 66:2302-10.

poolman B. 2002. Transporters and their roles in lab cell physiology. nt $J$
Gen Mol Microbiol 82:147-64. 作 the viscosity and structure of fermented milks. Int Dairy J 15:155-64. Shene C, Canquil N Bravo S, Rubilar M. 2008. Production of the exopolysaccharides by Streptococccus thermophilus: Effects of growth conditions on ferment
Microbiol 124:279-84 Control of lactose transport, $\beta$-galactosidase activity, and glycolysis by CCPA in Streptococcus thermophilus: evidence for carbon catabolite repression by a non-phosphoenolpyruvate-dependen

Dijkhuizen L. 1998. Screening and characterization of Lactobacillus strains producing large

Vaningelgem F, Zamfir M, Mozzi F, Adriany T, Vancanneyt M, Swings J, Vuyst $L$ de. 2004. Biodiversity of exopolysaccharides produced by Streptococcus thermophilus strains is reflected in their production and 70:900-12

Daddox IS, Archer RH. 2006. Metabolism associated with raised metabolic flux to sugar nucleotide precursors of Indust Microbiol Biotechnol 33:391-400.

Zisu B, Shah NP. 2003. Effects of $\mathrm{pH}$, temperature, supplementation with whey protein concentrate, and adjunct cultures on the production of
exopolysaccharides by Streptococcus thermophilus $1275 . \mathrm{J}$ Dairy Sci $86: 3405-15$

Zisu B, Shah NP. 2005. Textural and functional changes in low-fat mozzarella cheeses in relation to proteolysis and microstructure as influenced by the use 